\title{
An Input-output Analysis of China's Innovative Resources based on Knowledge Production Function
}

\author{
Kangshun Geng ${ }^{1}$ Jijian $\mathrm{Gu}^{* 2}$ \\ ${ }^{1}$ Modern Service Economy Research Center \\ Hubei Business College \\ Wuhan, China \\ ${ }^{2}$ School of Finance and Economics \\ Chongqing Vocational College of Transportation \\ Chongqing, China
}

\begin{abstract}
Under the background of the gradual disappearance of China's population dividend and the increasing restriction of resources and environment, economic development urgently needs to change from "factor driven" to "innovation driven". Research on the impact of innovation resources on economic growth is the key to the implementation of innovation driven strategy. According to the knowledge production function, innovation resources are divided into innovation material resources, innovation knowledge resources and innovation human resources. On this basis, the correlation and weight between the input and output of all kinds of innovation resources are investigated to explore the ideas and development direction of optimizing the allocation of innovation resources in China, and to provide practical basis for the formulation of relevant innovation incentive system.
\end{abstract}

\section{INTRODUCTION}

Since the reform and opening up, China's economy has continued to grow at a high speed for more than 30 years. However, under the influence of many factors, China has stepped into the "new normal" of economic development in recent years. Since the Chinese government launched the fiscal expansion policy of 4 trillion yuan in 2008, the expansion of government investment has temporarily solved the overcapacity of traditional industries, but also delayed the pace of China's industrial structure adjustment, resulting in the current situation of overcapacity and supply-demand contradiction more prominent [1].

China's economy is facing increasingly severe contradiction between supply and demand structure, and the problem of overcapacity caused by the government's expanding fiscal expenditure policy is increasingly prominent. China must realize economic transformation and upgrading to alleviate overcapacity and insufficient effective demand. In this process, factor driven and investment driven are weak, so innovation driven must be the core driving force.

The contradiction accumulated by long-term dependence on investment driven and extensive economic growth has become the bottleneck of sustained and stable economic growth [2]. Due to the low-end position of Chinese industry in the global value chain, the rise of factor price and the change of comparative advantage, the traditional Chinese economic development mode under the "new normal" needs to find a new driving force, namely innovation driving [3]. At present, China is facing the problem of failure of traditional economic growth mode and low matching of supply and demand. It is necessary to carry out supply side structural reform, with innovation driven as the core, to achieve economic transformation and upgrading [4].

In the context of innovation driven, how to optimize the allocation of innovation resources is an important issue to be solved. Innovation is an economic activity with input and output. In this process, all kinds of innovation resources are scarce. If we want to use the limited innovation resources on the blade, we must improve the allocation efficiency of innovation resources.

According to Griliches-Jaffe knowledge production function, this paper divides innovation resources into innovation material resources, innovation knowledge resources and innovation human resources, analyzes the input and output of various resources, and provides reference for the realization of innovation drive.

\section{INNOVATION RESOURCES}

\section{A. Knowledge Production Function}

Like the production of all products, the production of knowledge and technology is inseparable from the input of various elements and resources. The knowledge production function systematically describes the relationship between the input of factor resources and the

\footnotetext{
a79955004@qq.com

b*Correspondence author 406697814@qq.com
} 
output of innovation. Griliches first proposed the concept of knowledge production function. Its basic assumption is that the output of innovation process is regarded as a function of R \& D Investment [5]. Jaffe believed that R \& $\mathrm{D}$ investment should include $\mathrm{R} \& \mathrm{D}$ cost and $\mathrm{R} \& \mathrm{D}$ human resources, and improved Griliches' production function [6].

The general form of Griliches Jaffe knowledge production function is:

$$
Y=F(X, K, \mu)
$$

Where $\mathrm{y}$ is innovation output; $\mathrm{X}$ is input of traditional elements such as labor and capital; $\mathrm{K}$ is knowledge or technology level, which is used to measure input of knowledge resources; $\mu$ is residual.

The total factor productivity can be expressed as:

$$
A=Y / X
$$

The growth rate is:

$$
\tau=(d Y / d t) / Y-(d X / d t) / X
$$

$\mathrm{X}$ can also be expressed as:

$$
X=C^{s} L^{1-s}
$$

Among them, C represents capital element, L represents labor element, and $\mathrm{s}$ represents the share of capital element.

In the existing literature, Griliches Jaffe knowledge production function usually takes the form of C-D production function:

$$
Y=D C^{\alpha} L^{\beta} K^{\gamma} e^{\mu}
$$

Where $\mathrm{D}$ is a constant term, $\mathrm{t}$ is a time term, and $\alpha, \beta$, $\gamma$ are parameters to be estimated.

So the total factor productivity is:

$$
A=D X^{\alpha+\beta-1} K^{\gamma} e^{\mu}
$$

In the knowledge production function, the input of each factor is positively correlated with the output.

\section{B. Classification of Innovation Resources}

Innovation resources are the productive factors to support innovation activities. According to the knowledge production function, innovation activity is a process in which innovation resources are input to get innovation output. Therefore, according to Griliches-Jaffe knowledge production function, this paper divides innovation resources into innovation material resources, innovation knowledge resources and innovation human resources.

\section{1) Innovative material resources}

The concept of innovation material resources defined in this paper includes innovation material resources and innovation financial resources in a general sense. That is to say, innovative material resources include not only fixed assets such as scientific research instruments and equipment necessary for various innovative activities, but also various funds to support the smooth development of innovative activities. In the aspect of data processing, the innovation material resources can be monetized, which reflects the input of innovation subject to innovation activities in a certain period of time.

2) Innovative knowledge resources
Innovation knowledge resources refer to the sum of the existing knowledge and technology that can be used by the innovation subject and directly or indirectly invested in the innovation process. Existing knowledge and technology belong to the output of past innovation activities, so innovation knowledge resources are not only a part of innovation resources, but also the output of innovation activities. Both knowledge innovation and technology innovation are inseparable from the support of existing knowledge and technology.

In technological innovation, innovative knowledge resources cannot exist independently, and must be attached to a certain carrier. Further, innovation knowledge resources are composed of two parts: knowledge ontology and knowledge carrier: knowledge ontology refers to the knowledge itself invested in the innovation process, and knowledge carrier is a tool for storing knowledge resources, including books, CDs and even human brain.

From the micro level, according to the different dependent carriers, the innovation knowledge resources can be divided into two kinds: one is the innovation knowledge resources with material as the carrier, the other is the innovation knowledge resources with human as the carrier. The innovative knowledge resources based on material include papers, patents, production technologies, scientific works, etc., and the carriers can be paper, books, hard disks, optical disks, etc. No matter which carrier is adopted, it will not have a great impact on the value of knowledge. However, this kind of innovative knowledge resources cannot be directly put into innovation activities, which need to be absorbed and transformed by the workers in innovation activities, i.e. $\mathrm{R} \& \mathrm{D}$ personnel. The innovation knowledge resources based on human carrier are contained in the brains of the workers in innovation activities, which are invisible and abstract. Such resources include not only the knowledge that innovators learn through systematic education, but also the experience that innovators accumulate through practice.

3) Innovate human resources

Innovation human resource contains two meanings: one is the total number of people engaged in innovation activities in a certain time and space; the other is the total number of human capital of workers in innovation activities. Human capital is a collection of various knowledge, skills, experience and other factors on the carrier of human beings. It is acquired through acquired investment and efforts, and can bring value-added. That is to say, innovative human resources include not only the number of workers in innovation activities, but also the ability of workers to absorb and transform knowledge resources and put them into innovation activities. Innovative human resources cannot be simply equal to the labor force, but the combination of the total number of workers and their human capital in innovation activities. 


\section{INPUT-OUTPUT ANALYSIS}

\section{A. Variables and Sample Selection}

1) Innovation output: select new product sales revenue (Y1) of large and medium-sized industrial enterprises and the number of domestic approved registered trademarks (Y2) as indicators to measure technological innovation output.

2) Innovative material resources: select the internal expenditure $(\mathrm{K})$ of $\mathrm{R} \& \mathrm{D}$ funds of large and mediumsized industrial enterprises as the indicator to measure the input of technological innovation material resources.

3) Innovative human resources: select the full-time equivalent (L) of $\mathrm{R} \& \mathrm{D}$ personnel in large and mediumsized industrial enterprises as the indicator to measure the investment in technological innovation human resources.

4) Innovative knowledge resources: select the total number of Chinese papers (A) included in the three major search tools as the indicator to measure the technological innovation knowledge resources.

The above indicators are selected from the annual data of China in the past 20 years, which are sourced from the statistical yearbook of science and technology of China and the statistical yearbook of China. According to the nature of knowledge production function, the relevant data are taken as the logarithm.

\section{B. Multiple Regression}

Innovation production is different from the production of ordinary commodities. According to the general law of technological innovation, there is a certain time lag between the input of innovation resources into innovation output (such as patent application and authorization) and the receipt of economic returns (new products go on the market and gain profits). In the same year, the input of innovation resources usually takes the second year or more to get innovation output, and the time lag between the input of innovation resources and the economic return may be longer. The time lag of 1-5 years is often set in the input-output analysis of innovation.

This paper holds that the time lag between different technological innovation resources input and innovation output may be different and cannot be generalized. Therefore, in this model, we try different lag periods of 15 years for each innovation resource input, and select the best lag period according to AIC criteria. The results of multiple regression model are as follows.

TABLE I. THE RESULTS OF MULTIPLE REGRESSION MODEL

\begin{tabular}{|c|c|c|c|c|c|}
\hline $\begin{array}{c}\text { Dependent } \\
\text { Variable }\end{array}$ & $\begin{array}{c}\text { Explanatory } \\
\text { variable }\end{array}$ & Coefficient & Std. Error & t-Statistic & Prob. \\
\hline \multirow{4}{*}{ Y1 } & $\mathrm{C}$ & 4.192218 & 0.836713 & 5.010339 & 0.0004 \\
\cline { 2 - 6 } & $\mathrm{A}(-3)$ & -0.01154 & 0.013974 & -0.82576 & 0.4265 \\
\cline { 2 - 6 } & $\mathrm{K}(-4)$ & 1.377467 & 0.087795 & 15.68961 & 0.0000 \\
\cline { 2 - 6 } & $\mathrm{L}(-3)$ & -0.64904 & 0.278034 & -2.33439 & 0.0396 \\
\hline \multicolumn{5}{|c|}{$\mathrm{R}^{2}=99.5 \%$, Prob(F-statistic) $=0.0000$} \\
\hline \multirow{3}{*}{$\mathrm{Y} 2$} & $\mathrm{C}$ & 7.897653 & 2.935176 & 2.690691 & 0.0196 \\
\cline { 2 - 6 } & $\mathrm{A}(-3)$ & 0.007516 & 0.048933 & 0.153604 & 0.8805 \\
\cline { 2 - 6 } & $\mathrm{K}(-3)$ & 0.541025 & 0.261863 & 2.06606 & 0.0611 \\
\cline { 2 - 6 } & $\mathrm{L}(-3)$ & 0.277924 & 1.007123 & 0.275958 & 0.7873 \\
\hline \multicolumn{5}{|c|}{$\mathrm{R}^{2}=90.05 \%$, Prob(F-statistic) $=0.0000$} \\
\hline
\end{tabular}

1) Analysis of Innovative knowledge resources

It can be seen from TABLE I that whether the sales revenue of new products of large and medium-sized industrial enterprises (Y1) or the number of domestic approved registered trademarks (Y2) are used as the explained variables, the investment in technological innovation resources (A) fails to pass the t-test. Because this model regards the output of knowledge innovation as the input of technological innovation resources, the result shows that China's knowledge innovation cannot provide a good foundation for technological innovation.

2) Analysis of Innovative material resources and Innovate human resources

When the new product sales revenue (Y1) of large and medium-sized industrial enterprises is taken as the explanatory variable, the lag period of $\mathrm{K}$ and $\mathrm{L}$ is 4 and 3 periods respectively, in which $\mathrm{K}$ and $\mathrm{L}$ pass the t-test at the confidence level of $1 \%$ and $5 \%$, respectively, and the goodness of fit is $99.5 \%$. The coefficient of $\mathrm{K}$ is positive, which means that for every $1 \%$ increase in $\mathrm{K}$, $\mathrm{Y} 1$ will increase by $1.38 \%$. The coefficient of $\mathrm{L}$ is negative, which means that for every $1 \%$ increase in L, Y1 will decrease by $0.65 \%$. This violates the knowledge production function, that is, the input of innovation human resources is negatively related to innovation output.

Based on the availability of data, the innovation human resource index of this model selects the full-time equivalent of R \& D personnel to measure the number and time of labor in innovation activities; the concept of innovation human resource not only includes the number of workers themselves, but also includes the ability of workers to absorb and transform knowledge resources and put them into innovation activities, the latter is the human capital actually invested in innovation activities. This shows that the actual input of human capital in innovation activities is insufficient, and the allocation of innovation human resources measured solely by quantity is inefficient.

Observing the regression results of the second group of data, when the number of domestic approved registered 
trademarks (Y2) is taken as the explanatory variable, the lag period of $\mathrm{K}$ and $\mathrm{L}$ is three. Among them, $\mathrm{K}$ passes $\mathrm{t}$ test at $10 \%$ confidence level, and its coefficient is positive, which means that $\mathrm{Y} 2$ will rise $0.54 \%$ for every $1 \%$ increase of $\mathrm{K}$. However, $\mathrm{L}$ did not pass the t-test, indicating that $\mathrm{L}$ and $\mathrm{Y} 2$ were not correlated. This result also validates the conclusion of the first data model, that is, the allocation of innovative human resources measured solely by quantity is inefficient.

\section{Robustness Analysis}

In order to ensure the robustness of the correlation of the above variables, we eliminate the variables that fail the t-test and then build the regression model again. The results are as follows.

TABLE II. THE RESUltS OF ROBUSTNESS ANALYSIS

\begin{tabular}{|c|c|c|c|c|c|}
\hline $\begin{array}{l}\text { Dependent } \\
\text { Variable }\end{array}$ & $\begin{array}{c}\text { Explanatory } \\
\text { variable }\end{array}$ & Coefficient & Std. Error & t-Statistic & Prob. \\
\hline \multirow{3}{*}{ Y1 } & $\mathrm{C}$ & 4.192218 & 0.836713 & 5.010339 & 0.0004 \\
\hline & $\mathrm{K}(-4)$ & 1.377467 & 0.087795 & 15.68961 & 0.0000 \\
\hline & $\mathrm{L}(-3)$ & -0.64904 & 0.278034 & -2.33439 & 0.0396 \\
\hline \multicolumn{6}{|c|}{$\mathrm{R}^{2}=99.5 \%$, Prob(F-statistic $)=0.0000$} \\
\hline \multirow{3}{*}{$\mathrm{Y} 2$} & $\mathrm{C}$ & 7.897653 & 2.935176 & 2.690691 & 0.0196 \\
\hline & $\mathrm{K}(-3)$ & 0.541025 & 0.261863 & 2.06606 & 0.0611 \\
\hline & $\mathrm{L}(-3)$ & 0.277924 & 1.007123 & 0.275958 & 0.7873 \\
\hline
\end{tabular}

As shown in Table II, when the new product sales revenue (Y1) of large and medium-sized industrial enterprises is taken as the explained variable, the coefficient symbols of $\mathrm{K}$ and $\mathrm{L}$ remain unchanged after eliminating the variable a that fails the t-test. The conclusion is consistent with that before, that is, $\mathrm{K}$ is positively correlated with $\mathrm{Y} 1$, and $\mathrm{L}$ is negatively correlated with Y1. When the number of domestic approved registered trademarks (Y2) is taken as the explained variable, the coefficient symbol of $\mathrm{K}$ remains unchanged after the variables $A$ and $L$ that fail to pass the t-test are removed, and the conclusion is consistent with that before, that is, $\mathrm{K}$ and $\mathrm{Y} 2$ are positively correlated.

\section{Conclusion}

There is a disconnect between knowledge innovation and technology innovation in China. Knowledge innovation and technology innovation are fighting on their own, lack of integration mechanism, and cannot form a virtuous circle. The policy implication of this result is that the government should provide reasonable innovation management and incentive system, guide the integration of knowledge innovation and technology innovation, and form a virtuous circle between them.

The allocation of innovative material resources in China is effective, but the allocation of innovative human resources measured solely by the number of workers is inefficient. This conclusion has two policy implications: on the one hand, the government should encourage enterprises to further increase investment in innovative material resources, promote the growth of technological innovation output and optimize the allocation of innovative material resources through macro-control measures such as system supply; on the other hand, innovative human resources can not be simply equal to the number and working hours of workers in innovation activities, but also include innovation New personnel's human capital: the former's resource allocation is dominated by enterprises, while the latter's actual supply is provided by workers in innovation activities.

Therefore, to optimize the allocation of innovative human resources, first of all, the government is required to provide a perfect training system of innovative talents, so as to increase the potential human capital stock of the whole society; secondly, when the potential human capital stock of the whole society is fixed, enterprises are not only required to increase the number of workers, but also encouraged to give enough incentives to the owners of human capital in technological innovation activities, so as to increase the actual input of human capital in the process of innovation.

\section{Acknowledgment}

This research was supported by Humanities and Social Sciences Research Project of Hubei Provincial Department of Education under Grant No.18G132

\section{REFERENCES}

1. Li M., Zhang H., New Normal, New Opportunities and New Challenges: Restructuring the New Driving Force of Economic Growth, Economic Science, vol.6, 2014, pp.5-12.

2. Tang W., Fu Y., Wang Z., Technology Innovation, Technology Introduction and Transformation of Economic Growth Pattern, Economic Research Journal, vol.49, 2014, pp.31-43.

3. Gan C., China's Economic Transformation and Industrial Upgrading under the "New Normal", Journal of Nanjing University of Finance and Economics, vol.2, 2016, pp.1-10.

4. Wang X., Quan F., The Study of Innovation Path under the Supply-Side Structural Reform, Shanghai Journal of Economics, vol.3, 2016, pp.3-12.

5. Griliches Z., Issues in accessing the contribution of R\&D to productivity growth. Bell Journal of Economics, Vol.10, 1979, pp.92-116.

6. Jaffe A. B., Real effects of academic research. American Economics Review. vol.79, 1989, pp.984-1001. 